\title{
The Inca's ancient answer to food shortage
}

RESEARCHERS in a number of Latin American countries are looking at a crop first cultivated by the ancient Incas and then neglected for centuries, as a possible answer to the Andean region's acute shortage of locallyproduced food protein. The crop is quinoa (Chenopodium quinoa Willd.), a member of the Chenopodium or goose foot family, of which some 60 species are found around the world. Normally sown at altitudes of 2,000 to 4,000 metres, frost-resistant and able to thrive on poor soils with an annual rainfall as low as $300-400 \mathrm{~mm}$, its protein content averages about $14 \%$ and its lysine content $6 \%$. This makes it superior to most cereal grains in food value. In addition, it contains vitamin $\mathrm{C}$ and the $\mathrm{B}$ complex of thiamine, riboflavin and niacin.

Peru, Bolivia and Chile are all showing interest in this heritage of Inca agriculture. Bolivia has gone so far as to pass a law requiring the use of at least $5 \%$ of quinoa flour in commercially produced breads, pastas and other products. Chileans are using quinoa in feeding programmes to improve the nutrition of poor children. And Peru is trying to increase quinoa production as a means of reducing costly wheat imports.

Quinoa is used in food in a variety of ways, the main uses being in soups and sweets, and a coarse bread called 'kispina'. Various drinks can also be prepared, hot or fermented and high protein cakes and biscuits can be produced by mixing up to $60 \%$ quinoa flour with wheat flour. The nutritive value of noodles can also be considerably increased by using up to $40 \%$ quinoa flour without affecting the appearance or other characteristics of the end product. Quinoa flakes still retain a slightly bitter taste.

The leaves of the plant can also be eaten in salads and in certain regions where vegetables are scarce the leaves are important. The leaves and stalks are also fed to ruminants, and the chaff and gleanings from threshing are generally fed to pigs.

Along with the potato, quinoa is one of the earliest crops to have been cultivated in the high Andes. It was grown by Indians there long before the arrival of the Europeans and has remained a staple in spite of attempts to introduce European species. Archaeological evidence shows that chenopods were once used in Europe as grain, and various forms of the species are still grown today in hilly areas of north-west India. But the
Andes is the only area where quinoa become an important crop.

The plant is believed to have been domesticated from wild ancestors in highland areas of Bolivia, Colombia and Peru. Unlike potatoes and maize, it was ignored by the Spaniards, and this neglect has continued until recently. The first interest stirred among researchers in Bolivia and Peru in 1965 , leading to the development of improved varieties and better

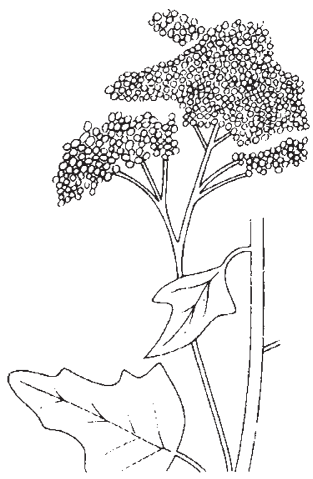

Chenopodium quinoa infructescence

knowledge of the major characteristics of the plant, its cultivation and limitations.

\section{Yields and growing conditions}

Yields vary greatly according to growing conditions-from as low as 450 kilograms per hectare to as high as 2,000 . The average yield is about 800 to $1,000 \mathrm{~kg}$ per ha on the altiplano. But a record yield of about $5,000 \mathrm{~kg}$ per ha has been reported under ideal conditions near Lake Titicaca, using the new variety Sajama developed in Bolivia.

Highland farmers often cultivate quinoa in rotation with other crops beccause they believe it can prevent disease among other crops. (Quinoa itself is prey principally to mildrew and leaf spot, though its most serious enemies are birds).

Tests with rats have shown that quinoa can improve the nutritive value of cereal-based diets. Wheat flour mixed with quinoa flour at a ratio of 4:1 improved nitrogen efficiency for growth by $40 \%$, weight gain by $11 \%$, and protein efficiency ratio by $72 \%$ over wheat flour alone.

In reports of poultry feeding trials in Bolivia, chicks fed a ration containing cooked quinoa made gains equal to those receiving corn and skimmed milk. But rations containing uncooked quinoa depressed the rate of weight gain of both chicks and swine.

What makes the difference in growth patterns is the presence of saponins, glucosides that are found in the seedcoat of quinoa. These can be re- moved by washing or cooking, which removes both the saponins' bitter taste and the toxic effects, which depress growth. In Peru machines have been developed for large-scale processing of quinoa in industry, for example for wheat-quinoa flour mixes. Saponin-free varieties can also be developed, such as the Bolivian variety Sajama. Unfortunately, most of the large-grained varieties now in use have a relatively high saponin content.

\section{Research on quinoa}

Serious research into the improvement of quinoa began in 1965 at the Patacamaya Research Station in Bolivia, with the support of Oxfam and the United Nation's Food and Agricultural Organisation. The station now has a collection of some 700 different ecotypes taken mainly from farmers' fields. Another collection in Puno, Peru, contains sotme 600 entries, and additional collections are being undertaken. Analysis of these collections is producing an evaluation of the genetic diversity of the plant and could lead to selection of cultivars with desirable characteristics.

The first international convention on chenopods was held at Puno in 1968 and attended only by a small group of researchers, mainly from Bolivia and Peru. A much larger attendance and broader representation was achieved at the second international meeting held in Bolivia in 1975.

Last year, Canada's international Development Research Centre (IDRC) agreed to support an expanded research programme based at the Patacamaya station of the Bolivian Institute of Agricultural Technology. The programme is designed to develop new quinoa varieties adapted to different agro-ecological production zones in Bolivia and elsewhere; develop economic production packages for farmers; and provide training for Bolivian researchers.

Production in Bolivia is currently insufficient to meet the demand created by the law requiring $5 \%$ quinoa flour in commercially baked goods, so the research takes on added importance. Research has also been underway at the University of Peru since 1976, supported by the Simon Bolivar Fund and administered by the Inter-American Institute for the Agricultural Sciences.

Edward J. Weber

The author is Senior Programme Officer, Agriculture, Food and Nutrition Sciences Division, Latin American Regional Office, International Development Research Centre, Bogota, Colombia 